\title{
Ocular toxocariasis in adults
}

\author{
E. R. RAISTRICK AND J. C. DEAN HART \\ From the Department of Ophthalmology, Bristol Eye Hospital, Bristol
}

The larva of the nematode Toxocara canis was first identified as a cause of intraocular disease by Nichols (1956). Subsequent studies showed that it may produce a variety of ocular lesions, including localized retinal granulomata (Ashton, 1960), endophthalmitis (Irvine and Irvine, 1959; Duguid, I961a), or papillitis (Bird, Smith, and Curtin, 1970). Nearly all the reported cases are of ocular lesions in children (Wilkinson and Welch, 1971), and the inference has been that the unhygienic habits of infants coming into contact with infected dogs, or soil contaminated with the ova of the nematode, is a major factor in limiting ocular disease to the young (Duguid, 196rb; Unsworth, Fox, Rosenthal, and Shelton, 1965). However, the proportion of the population with antibodies to Toxocara species increases with age. In a study of healthy blood donors in the age group $18-25$ years toxocaral fluorescent antibody tests were positive in 4.5 per cent and this figure rose to $7 \cdot 1$ per cent in the 30-40 age group (Woodruff, I973). Clearly adult toxocaral infection also occurs.

Clinical reports of retinal lesions in adults due to presumed toxocaral infection are few. Phillips and MacKenzie (1973) described the case of a 25-year-old woman who presented with a history of recent uniocular visual deterioration and was found to have a right papillitis. Initial toxocaral fluorescent antibody tests were negative, but later they were positive. More recently, another case was reported of a 50-year-old man who developed moderate deterioration of vision in his right eye after a short febrile illness. He had a right pigment epithelial detachment adjacent to the macula and a linear opacity in the centre of the lesion changed its orientation over a period of days. $\mathrm{He}$ had a transient eosinophilia and toxocaral fluorescent antibody tests were positive (Raistrick and Dean Hart, 1975).

In this paper the ocular findings in three patients in the age group 20-29 years who complained of relatively sudden uniocular visual loss are described. All had posterior polar retinal lesions in the affected eyes, and ophthalmoscopic findings closely

Address for reprints: Mr J. C. Dean Hart, Bristol Eye Hospital, Bristol BSI 2LX resembled those of proved toxocaral granulomata in children (Ashton, 1960). In all cases the toxocaral fluorescent antibody tests were positive.

\section{Case reports}

CASE I

A 20-year-old woman secretary with a record of good health complained in June 1972 of deteriorating vision in the left eye over a period of four weeks and intermittent, left-sided frontal headaches. Her corrected visual acuities were $6 / 5$ right and less than 6/60 left. The right eye was normal on biomicroscopy and ophthalmoscopy, but in the fundus of the left eye there was a raised pigmented lesion involving the macula. Near to it were a few small, deep retinal haemorrhages and the surrounding retina appeared oedematous (Fig. 1a). There was a dense central scotoma of the left eye. $X$-ray examination of chest and skull showed no abnormalities and an ESR, a full blood count, and a dye test for toxoplasma were all within normal limits. No diagnosis was made and therefore no treatment instituted. Five months later the vision had improved spontaneously to $6 / 12$ in the affected eye, though the retinal lesion appeared to be somewhat more extensive.

In January 1973 the left vision had fallen to $6 / 18$ and the patient was admitted to hospital for further assessment. A general physical examination showed no positive findings. A short trial of systemic corticosteroid therapy failed to ameliorate her symptoms and her vision continued to deteriorate. Some nine months later the left acuity was reduced to counting fingers and the lesion now appeared as a raised white opaque, umbilicated swelling with clearly defined edges. A previously noted retinal blood vessel that crossed over the margin of the mass and dipped into the depressed central area had become grossly dilated (Fig. $1 b$ ). As the lesion on ophthalmoscopic examination closely resembled an illustration of toxocaral granuloma in a child described by Ashton (1960) we performed a toxocaral fluorescent antibody test. This was positive. On subsequent questioning the patient admitted close contact with a dog a few months before the onset of the symptoms.

In November 1974 the retinal lesion had flattened somewhat and the engorged blood vessel returned to its original calibre (Fig. Ic). Six months later the patient's central vision remained grossly impaired, but the lesion involving the macula was much flatter. Surrounding pigmentary changes were now obvious. Seven 
(a)

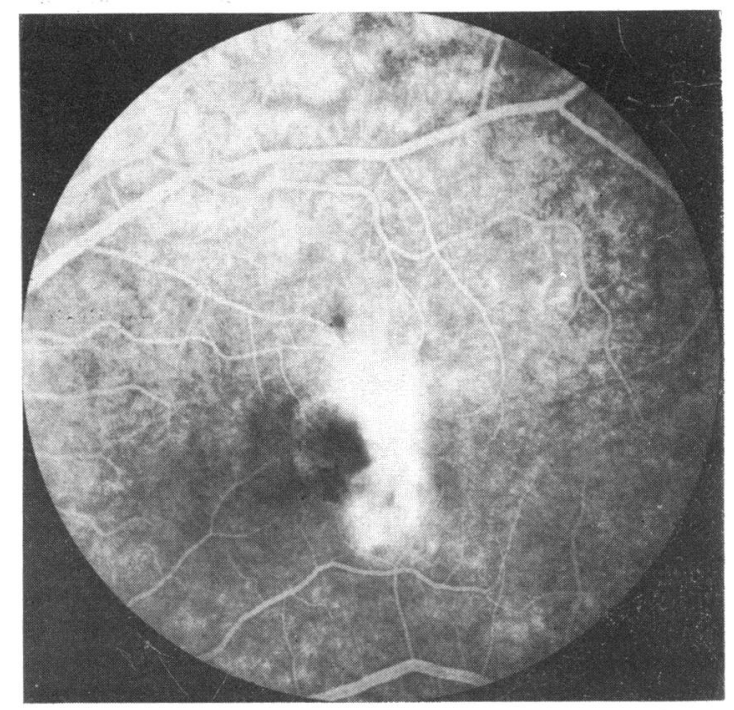

(c)

months afterwards there was retinal scarring involving the macula with further progression of pigmentary disturbances at the posterior pole (Fig. Id).

\section{Fluorescein angiography}

Fluorescein angiography soon after the patient was first seen showed, in the initial part of the dye transit, masking of the choroidal fluorescence at the site of the pigmented lesion with no abnormality of the overlying retinal vessels. In the venous and late phases there was progressive uptake of dye in the central area of the mass (Fig. 2a, $b, c$ ). Angiograms repeated in December I 975 showed changes associated with pigment epithelial

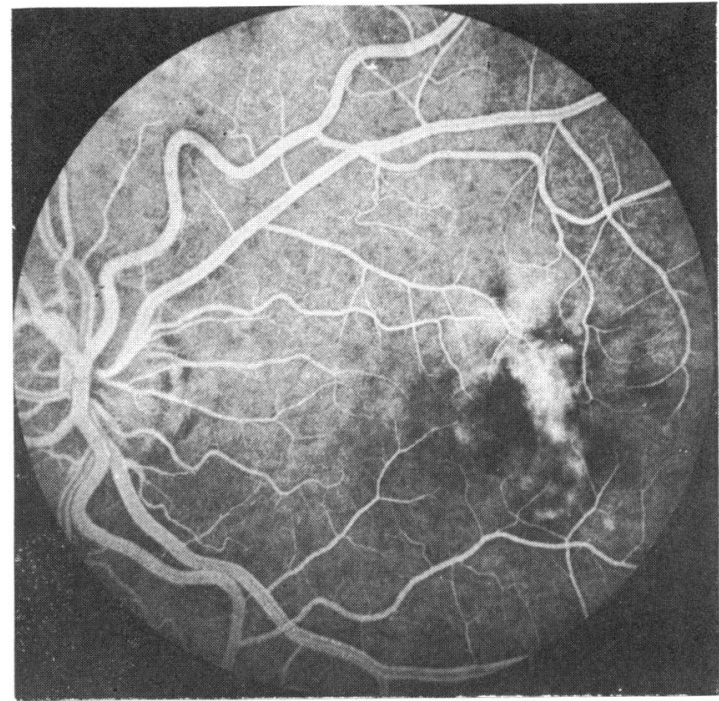

(b)

FIG. 2 Case 1 . Left retinal fluorescein angiogram sequence on presentation. (a) Early arterial phase. (b) Venous phase. (c) Residual phase. Initial choroidal masking of region occupied by lesion and subsequent leakage of fluorescein dye at site of mass

clumping and atrophy localized to the posterior pole (Fig. $3 a, b$ ) with minimal uptake or leakage of dye.

CASE 2

A 25-year-old man, a driver, was referred in August r 973 with a few weeks' history of intermittent rightsided frontal headaches, occurring mostly in the evenings, and a progressive loss of central vision in his right eye. There was no history of general symptoms and his medical history was unremarkable. His left visual acuity was $6 / 4$ and the right was reduced to counting fingers. The left eye showed no abnormal features, but ophthalmoscopy of the right fundus 

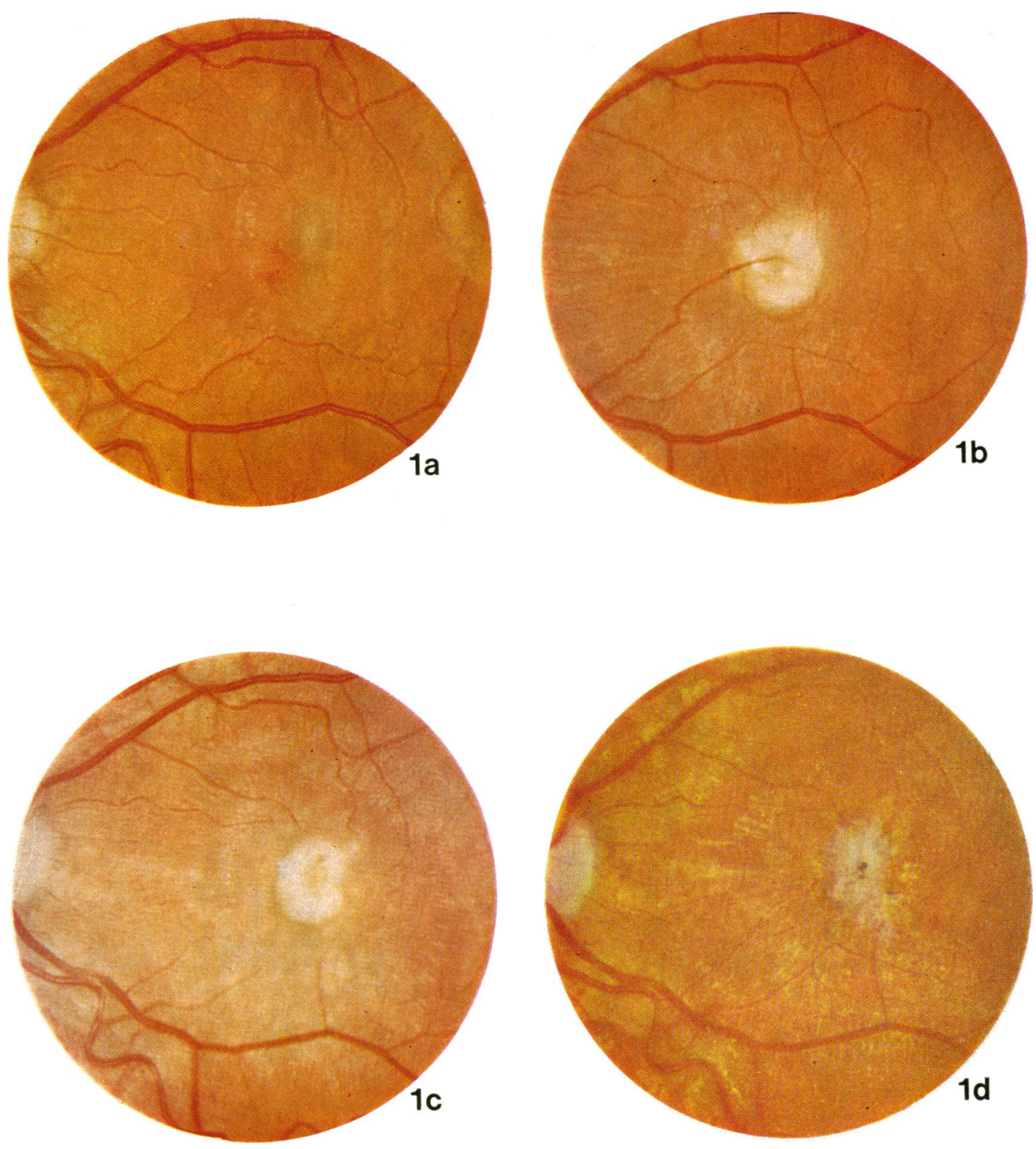

FIG. I Case 1. Changes in appearance of left posterior polar lesion involving the macula. (a) On presentation. (b) After 5 months. (c) After 27 months. (d) After 40 months

showed gross swelling of the optic disc and a small pigmented lesion on its temporal side (Fig. 4). The superficial disc capillaries appeared engorged and retinal folding could be seen between the pigmented mass and the disc. A papillitis or tumour involving the optic nerve head was tentatively diagnosed and the patient admitted to hospital for further investigations.

General physical and neurological examination was negative, as were the results of $x$-ray examination of skull and optic foramina, carotid angiograms, and air encephalograms. A full blood count and plasma viscosity estimation were within normal limits. A trial of systemic corticosteroids produced no improvement in symptoms. When seen in January 1974 the patient's visual status had not altered. The disc, however, appeared less swollen and the pigmented area temporal to the disc was more obvious and clearly defined. He had an eosinophilia of 8 per cent and a toxocaral fluorescent antibody test proved positive. The patient denied recent contact with dogs or puppies. Subsequent examinations at 


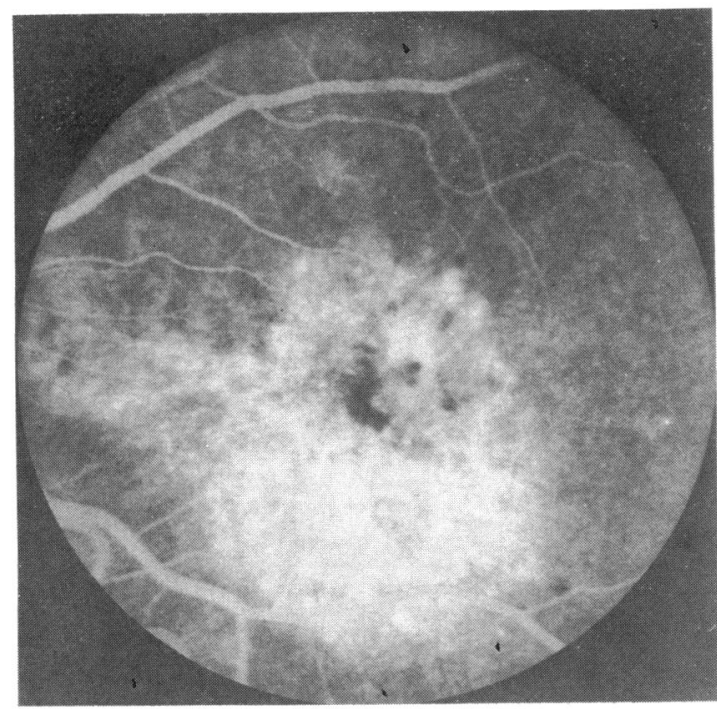

(b)

FIG. 3 Case I. Left retinal fluorescein angiograms at 40 months. (a) Early arterial phase. (b) Residual angiogram. Extensive retinal pigmentary disturbances are now an obvious feature, with minimal uptake or leakage of dye in residual phase

six-monthly intervals showed a gradual decrease in disc swelling and progressive pigmentation of the retina temporally.

\section{Fluorescein angiography}

Fluorography of the right retina in August 1973 showed dilatation of the prepapillary capillary plexus and masking of the choroid in the region of the pigmented

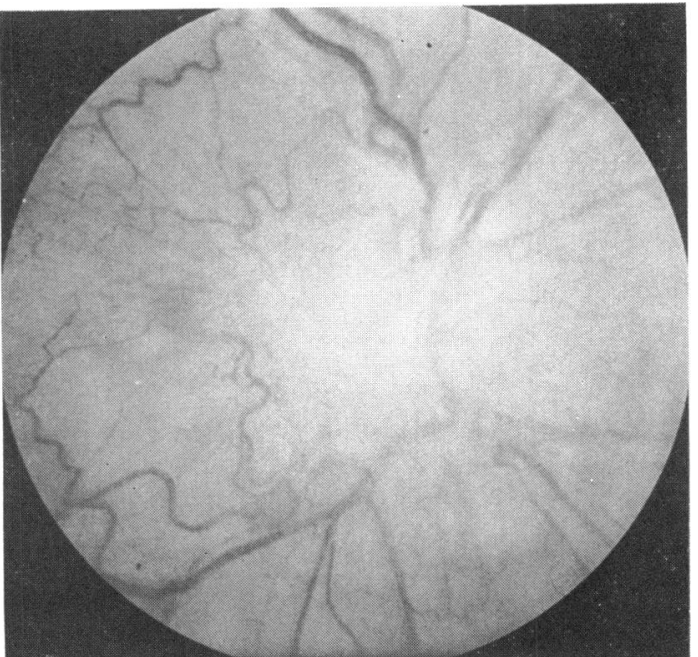

FIG. 4 Case 2. View when patient presented of right swollen disc and mass at 9 o'clock

lesion in the early phase of the transit. In the residual phase there was profuse leakage of dye from the disc capillaries and uptake of fluorescein in the centre of the pigmented lesion (Fig. 5a,b). Fluorescein studies in November 1975 showed that the dilated capillaries overlying the disc were less prominent than before, with reduced leakage of dye from these vessels. There were extensive pigmentary disturbances in the area around the retinal lesion described on presentation but no leak or uptake of dye was recorded.

\section{CASE 3}

A 20-year-old bank clerk was seen at the Bristol Eye Hospital in November 1974 with a history of gross impairment of left central vision of nine months' duration. Visual loss had been rapid. He had no other symptoms and his health had been good. He had initially attended another eye unit, where retinochoroiditis had been diagnosed. It was first thought that the retinal changes might be due to Histoplasmosis capsulatum infection, but a histoplasmin test was negative, as was a Mantoux test. A full blood count showed nothing abnormal. On examination in Bristol his right visual acuity was $6 / 6$ and his left was hand movements. A large left central scotoma was plotted. No abnormalities were noted in the anterior segment or vitreous of his left eye, but ophthalmoscopy showed a raised pale area involving the macula, with surrounding pigment changes and some small retinal haemorrhages around the periphery of the lesion (Fig. 6). No abnormal features were found in the right eye. A toxocaral fluorescent antibody test was positive. The patient admitted frequent contact with a dog at his parents' home.

When seen in October 1974 his visual status remained unaltered but the changes at the posterior pole covered a wider area with obvious retinal pigmentary disturbances. Nine months later his visual acuity had not 


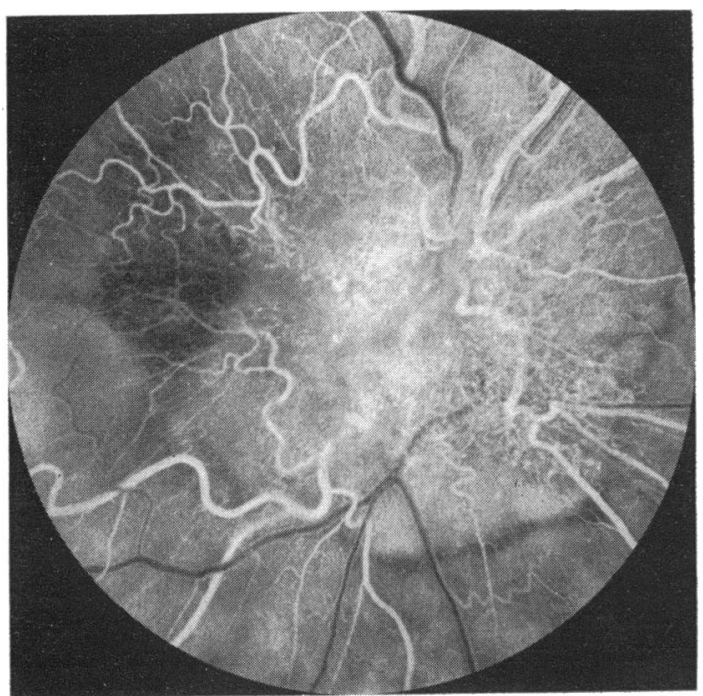

(a)

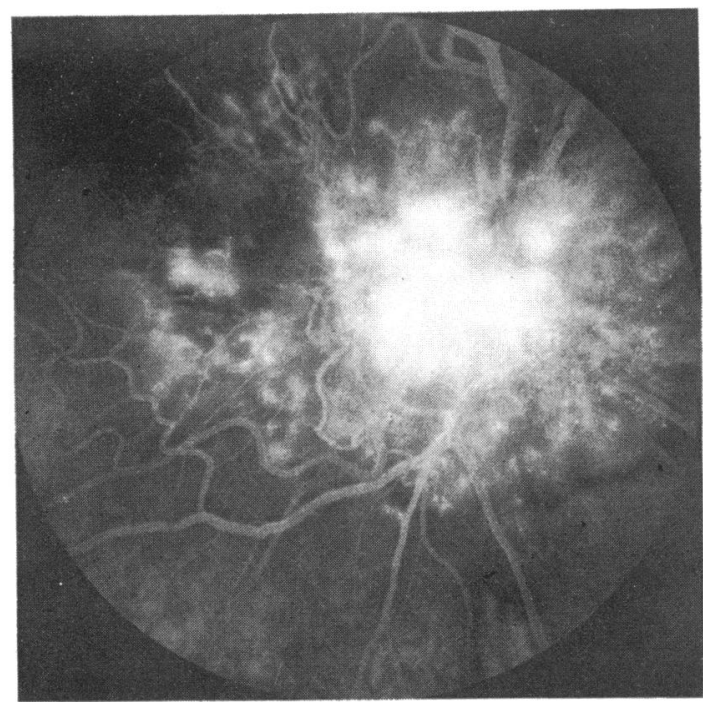

(b)

FIG. 5 Case 2. Retinal fluorescein angiograms on presentation. (a) Early venous phase. (b) Residual angiogram. Prepapillary capillary plexus dilated. Massive leakage of fluorescein dye from these vessels is prominent feature in residual angiogram

improved. Although the mass appeared flatter than on presentation pigmentation of the retina continued to progress.

\section{Fluorescein angiography}

Retinal fluorography on his first visit to the Bristol Eye Hospital showed early masking of the choroidal fluorescence in the left eye and a later uptake of dye in

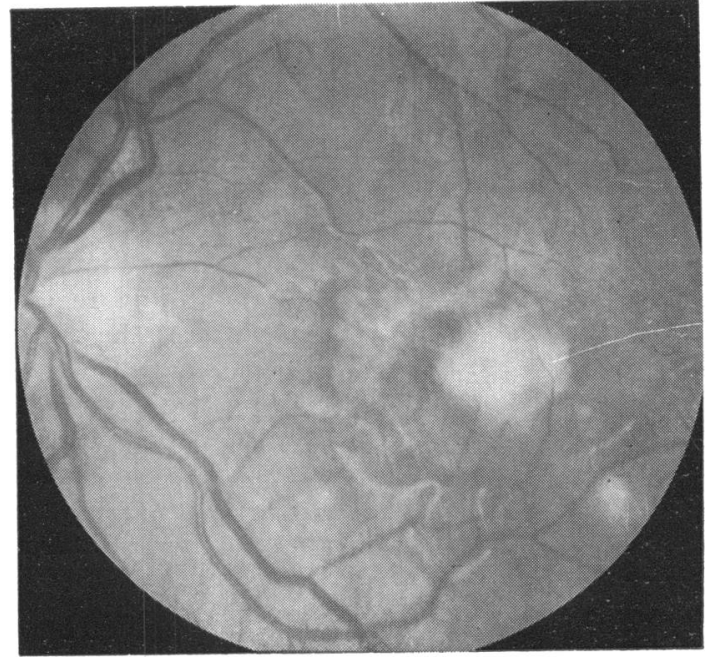

FIG. 6 Case 3. Left eye on presentation. View of pale raised lesion involving macula

the centre of the lesion as described in cases 1 and 2 . Repeat angiograms in July 1975 showed merely a localized pigmentary disturbance without leak or uptake of dye.

\section{Discussion}

The ophthalmoscopic appearances of toxocaral retinal granulomata at the posterior pole were described in four children by Ashton (1960). He reported retinal lesions which were solitary, pale, discrete, circular, and raised. Blood vessels prominent on the edge of the mass became lost from view in the central area in two cases, and retinal haemorrhages adjacent to granulomata were reported in two further cases. The initial retinal findings in the adults reported in this series showed many of the features mentioned by Ashton. Moreover, we have followed the progressive nature of the retinal lesion in case $I$ for $3 \frac{1}{2}$ years from almost the initial to a late, less active stage. We believe that all three cases show manifestations, on presentation and later, which fit into a definite clinical pattern not previously described in adults.

On entering the systemic vascular circulation the second stage toxocaral larva is washed along in the blood stream until arrested in a vessel whose calibre permits no further progress. The organism, a very active borer (Sprent, I954), then passes through the vessel wall and takes up a position deep in the tissues, where it may remain alive for a long time. We suggest that retinal haemorrhages produced by the passage of the larva through the vessel wall and sudden subsequent movements of a foreign organism adjacent to the macula 
could cause the initial retinal visual disturbances, and that as the parasite becomes less active retinal function may transiently improve, as in case $I$.

Eventually, however, the larva dies and disintegrates, prompting an intensified tissue response which leads to focal disruption of the neural layers of the retina (Ashton, 1960) and disturbances of the pigment epithelium. During this active inflammatory stage increased vascularity in the region of the mass might be expected, and the local vascular dilatation in cases $I$ and 2 suggests that a similar process could have happened in these patients. Later, as the cellular activity becomes reduced, flattening of the mass occurs, the vessels return to their previous calibre, and disturbances of the pigment epithelium promoted by the earlier inflammatory response appear more obvious and widespread.

The fluorescein studies in all cases showed initial masking of the choroidal phase at the site of the pigmented lesion due to thickening or opacification, or both, of the overlying retina, and the localized hyperfluorescence in the residual phase probably resulted from uptake of dye into cystic spaces or staining of inflammatory tissue. Later studies showed extensive pigmentary disturbances at the posterior pole with no leakage of fluorescein dye, corresponding to a less active phase of the disease process. In case 2 marked dilatation of the prepapillary capillary plexus was a prominent feature, and possibly the process was fairly active when the patient first presented. The initial ophthalmoscopy changes were similar to those in a case of nematode optic neuritis reported by Bird and others (1970).

Unilateral ocular pain or headache was a prominent symptom in two of our patients. Severe retro-ocular pain was completely relieved within 24 hours by vigorously light-coagulating the site presumed to be occupied by a larva in a patient who presented with evidence of toxocariasis (Raistrick and Dean Hart, 1975). Apparently the living organism may cause this symptom, since ocular pain was also relieved after thiabendazine treatment in a presumed case of ocular toxocaral infection (Unsworth and others 1965).

The soil of many recreational areas in and around towns and cities of the United Kingdom is heavily contaminated with the live ova of toxocara. Borg and Woodruff (1973) found ova of Toxocara species in 24.4 per cent of 800 soil samples taken from public places. As such open spaces are used for picnics and sporting activities there is ample opportunity for ova to enter the human body. Children of dog owners may no longer be assumed to be the only section of the community exposed to this hazard, nor can the absence of a history of contact with animals that might harbour the parasite exclude the diagnosis.

Although histological verification of toxocaral lesions involving the retinae of adults is lacking toxocara larvae were probably alone responsible for the lesions in our patients, and this diagnosis should be considered in adult patients presenting with similar symptoms and signs.

\section{Summary}

Human infection by toxocara larvae has been thought to be predominantly a disease of young children, but the percentage of the population with antibodies to this nematode worm has recently been shown to increase with age. Although a definite diagnosis of ocular toxocariasis can be made only by identifying the larva histologically, the evidence in three cases presenting with recent uniocular loss of vision strongly suggests that adults may also be affected. The lesions noted on ophthalmoscopy closely resembled toxocaral granulomata in children. Toxocaral fluorescent antibody tests were positive in each case.

We thank Professor A. W. Woodruff for advice and his staff for performing the toxocaral fluorescent antibody tests. We thank Mr J. Morgan for photographic services, and Mrs M. Roach for her secretarial help.

\section{References}

Ashton, N. (1960) Brit. F. Ophthal., 44, 129

BIRD, A. C., Smith, J. L., and CURTin, v. T. (i970) Amer. J. Ophthal., 69, 74

BORG, O. A., and WOODRUFf, A. W. (1973) Brit. med. F., 4, 470

DUGuid, I. M. (I96ra) Brit. F. Ophthal., 45, 705

( $196 \mathrm{Ib})$ Ibid., 45, 789

IRVINe, w. C., and IRVINE, A. R. (1959) Amer. F. Ophthal., 47, I 85

NICHOLS, R. L. (I956) $\mathcal{F}$. Parasit., 42, 349

PHILliPS, C. I., and MACKENZIE, A. D. (1973) Brit. med. F., I, I 54

RAISTRICK, E. R., and DEAN HART, J. C. (I975) Ibid., 3, 4 I 6

SPRENT, J. F. A. (I954) f. Parasit., 40, 608

unsworth, A. C., Fox, J. C., Rosenthal, E., and Shelton, P. A. (1965) Amer. J. Ophthal., 60, 127

WILKINSON, C. P., and WELCH, R. B. (I97I) Ibid., 7I, 92 I

WOOdRuff, A. W. (I973) Trans. roy. Soc. trop. Med. Hyg., 67, 755 